\title{
MIC database: A collection of antimicrobial compounds from literature
}

\author{
Padavala Ajay Babu ${ }^{1 *}$, Palakeerthi Srinivas Kumar ${ }^{1}$, Polumati Padmaja ${ }^{1}$, T Khageswara Rao ${ }^{1}$, Sashikanth Chitti ${ }^{1}$ \\ ${ }^{1}$ Translational Research Institute of Molecular Sciences (TRIMS), Bioinformatics Division, 2-35-72, MVP Colony, Sector-10, Visakhapatnam - \\ 530017, India; Padavala Ajay Babu - Email: ajay@trimslabs.com; Phone: +91-891-6691882; *Corresponding author
}

Abstract:

Received June 11, 2009; Revised July 23, 2009; Accepted July 25, 2009; Published September 05, 2009

We describe a database named MIC database containing 2-dimensional structures of synthesized compounds/antibiotics, IUPAC name, smiles notation and the MIC values / zone of inhibition against a particular organism, strain and culture conditions. The data was collected from various literature sources such as Arkivoc, Bioorganic Medicinal Chemistry Letters, Antimicrobial Agents and Chemotherapy, Journal of Clinical Microbiology and Journal of Bacteriology. MIC Database can be accessed at www.trimslabs.com/mic/index.htm.

Keywords: database; anti-microbial; literature; medicinal

\section{Background:}

One of the major problems in antibacterial chemotherapy is bacterial drug resistance. It is referred to as a condition in which there is no susceptibility or decreased susceptibility to antibacterial agents and is a quantitative measurement of the efficiency of an agent against a specific bacterium, generally expressed in $\mathrm{g}$ or $\mathrm{mg}$ per $\mathrm{ml}$ or as zones of inhibition (ZI) in mm. Experimental determinations of antibacterial activity are based on testing gradually increasing concentrations of potent chemical compound against the microorganism under study to find out the concentration at which the growth is inhibited, reported as the minimum inhibitory concentration (MIC) of the drug [1]. MIC is the lowest concentration of an antimicrobial agent, generally a chemical compound or an antibiotic, that inhibits the growth of microorganisms after a period of incubation, determined either by agar or broth dilution methods [2]. MICs have been featured as an important test in diagnostic laboratories to evaluate the activity or resistance of microorganisms to an antimicrobial agent [3]. MIC has been regarded as the most basic laboratory measurement of activity of an antimicrobial agent against various mircroorganisms and rapid advances in microbiology have resulted in a large increase in a number of potent chemical compounds being synthesized as possible antimicrobial agents. Here, we present a database of chemical compounds tested for their antimicrobial activities.

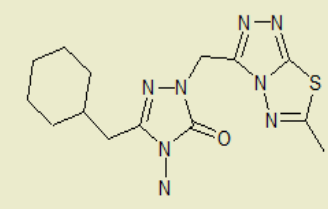

\begin{tabular}{|c|l|}
\hline \multicolumn{1}{|c|}{ ID: } & MIC.C.5 \\
\hline LIPINSKI DATA: & \\
\hline Mol Wt & 348.48 \\
\hline Log P & 2.9196 \\
\hline HBA & 6 \\
\hline HBD & 1 \\
\hline Rotatable Bonds & 4 \\
\hline
\end{tabular}

IUPAC 4-amino-5-cyclohexylmethyl-2-(6-methyl-[1,2,4]triazolo[3,4-b][1,3,4]thiadiazol-3-ylmethyl)-2,4dihydro-[1,2,4]triazol-3-one

SMILES

REPORTED ACTIVITY

\section{$\mathrm{C} 1 \mathrm{CCCC}(\mathrm{C} 1) \mathrm{CC}=4 \mathrm{~N}(\mathrm{C}(\mathrm{N}(\mathrm{Cc} 2 \mathrm{n} 3 \mathrm{nc}(\mathrm{C}) \operatorname{sc} 3 \mathrm{nn} 2) \mathrm{N}=4)=0) \mathrm{N}$}

Therapeutic effects for inflammation, cancer, pain, tuberculosis, hypertension, anti-bacterial, antdepressant, anti-viral, anti-tumoral, anti-inflammatory agents, pesticides, herbicides, dyes,

lubricant, analytical agents.

\section{Activity data:}

\begin{tabular}{|c|c|c|c|}
\hline Method / Technique & Organism- Strain & $\begin{array}{c}\text { MIC } \\
(\mu \mathrm{g} / \mathrm{ml})\end{array}$ & Culture Conditions * \\
\hline Double dilution & $\begin{array}{c}\text { E. coli ATCC } 25922 \\
\text { K. pneumoniae ATCC } 13883 \\
\text { Y. pseudotuberculosis ATCC } 911 \\
\text { P. aeruginosa ATCC } 10145 \\
\text { E. faecalis ATCC } 29212 \\
\text { S. aureus ATCC } 25923 \\
\text { B. subtilis ATCC } 6633\end{array}$ & $\begin{array}{l}39 \\
39 \\
312 \\
625 \\
9 \\
9 \\
4\end{array}$ & Mueller-Hinton broth at $\mathrm{pH} 7.3$ \\
\hline
\end{tabular}

Figure 1: Screen-shot image of an entry in MIC Database. 


\section{Bioinformation}

Methodology:

Construction of database

The MIC database was constructed using html and can be accessed at http://www.trimslabs.com/mic/index.htm. Data were collected from different journals such as Bioorganic \& Medicinal Chemistry Letters [4], Arkivoc [5], Microbiology and Immunology, Journal of Dairy Science, Antimicrobial Agents and Chemotherapy, Journal of Antimicrobial Chemotherapy, Journal of Clinical Microbiology, Journal of Bacteriology, Applied and Environmental Microbiology and Indian Journal of Pharmaceutical Sciences. Currently, MIC database includes 500 records of various chemical compounds tested against nearly 80 microorganisms.

\section{Database features:}

The data were categorized based on the molecular weights of all compounds for ease of access. Each entry in the database was provided with unique accession numbers viz. MIC.A.XX where $\mathrm{XX}$ represents the data entered under category ' $A$ ' (Table 1 in supplementary material). Each entry is associated with the 2 dimensional structure, Lipinski's data, IUPAC (International Union of Pure and Applied Chemistry) name, smiles representation, reported activity and the MIC values against a particular organism, strain and culture conditions, respectively. A screen-shot of the database is given in Figure 1.
Utility:

Antibacterial agents are being used for various purposes in the laboratories and to treat many microbe related diseases in humans. This database finds utility in the sceintific community for a quick view of the collection of various antibacterial agents and the organisms. Moreover, the data was segregated based on the molecular weights, which provides an easy way of access as well as locating the data in the database. References are provided for each compound in the database so as to track the published data.

\section{Future development:}

Till date the data were collected from about 10 journals, however, work is in progress to append the data from various other journals and literature sources. The database shall be updated regularly.

\section{References}

[1] H Ericsson, JC Sherris, Acta Pathol Microbiol Scand Sect B, 217:1 (1971)

[2] FG Witebsky et al., J. Clin. Microbiol. 5:589 (1979) [PMID: PMC275353].

[3] JM Andrews, J. Antimicrob. Chemother. 48:5 (2001) [PMID 11420333]

[4] http://www.elsevier.com/locate/bmcl/

[5] http://www.arkat-usa.org/

Edited by P. Kangueane Citation: Babu et al., Bioinformation 4(2): 75-77 (2009) License statement: This is an open-access article, which permits unrestricted use, distribution, and reproduction in any medium, for noncommercial purposes, provided the original author and source are credited. 


\section{Bioinformation}

open access

www.bioinformation.net

Database

Supplementary material:

Table 1: Data categorization based on molecular weights of antimicrobial compounds in MIC database

\begin{tabular}{lclr}
\hline Molecular weight (KDa) & Category & \multicolumn{1}{c}{ Data } & No. of Compounds \\
\hline$<200$ & A & MIC.A.01 - MIC.A.16 & 16 \\
$201-300$ & B & MIC.B.01 - MIC.B.74 & 74 \\
$301-400$ & C & MIC.C.01 - MIC.C.220 & 220 \\
$401-500$ & D & MIC.D.01 - MIC.D.100 & 100 \\
$501-600$ & E & MIC.E.01 - MIC.E.42 & 42 \\
$601-700$ & F & MIC.F.01 - MIC.F.16 & 16 \\
$701-800$ & G & MIC.G.01 - MIC.G.10 & 10 \\
$801-900$ & H & MIC.H.01 - MIC.H.16 & 16 \\
$901-1000$ & I & MIC.I.01 - MIC.I.03 & 03 \\
$>1000$ & J & MIC.J.01 - MIC.J.03 & 03 \\
\hline
\end{tabular}

